\title{
A mudança de compreensão de um formando em Educação Física acerca do sentido do componente curricular na escola: uma autoetnografia
}

\section{RESUMO}

Esta pesquisa teve como objetivo identificar quais fatores induziram uma mudança conceitual de um formando em Educação Física, em relação à compreensão do sentido desse componente curricular na escola. Por meio de uma autoetnografia, durante 11 meses o autor analisou os trabalhos realizados em tarefas acadêmicas, as anotações em cadernos de disciplinas cursadas, as intervenções efetuadas como trabalho de campo e os questionários respondidos pelos seus alunos. Os resultados indicam que não foi um acontecimento único que induziu a mudança de compreensão, mas vários fatores. $\mathrm{O}$ principal deles foi a discussão, em um componente curricular, sobre o direito de aprendizagem dos discentes. Em menor medida, as intervenções nos trabalhos de campo realizadas em virtude de disciplinas acadêmicas, a constatação do interesse dos alunos ao experimentarem temas de ensino distintos dos que estavam acostumados e a testagem de conhecimentos estudados na universidade com seus próprios filhos, tiveram influência na mudança conceitual.

PALAVRAS-CHAVE: Educação física escolar; Práticas tradicionais; Mudança de concepção; Práticas inovadoras; Autoetnografia
Anderson Henrique Rozek Mallmann

Graduado em Licenciatura em Educação Física Universidade Regional do Noroeste do Estado do Rio Grande do Sul - Unijuí, Ijuí/RS, Brasil andersonmallmann@hotmail.com https://orcid.org/0000-0002-3425-9200

Fernando Jaime González

Doutor em Ciências do Movimento Humano Universidade Regional do Noroeste do Estado do

Rio Grande do Sul - Unijuí, Ijuí/RS, Brasil fjg@unijui.edu.br https://orcid.org/0000-0002-7033-663X

Robson Machado Borges

Doutor em Ciências do Movimento Humano Universidade Regional do Noroeste do Estado do Rio Grande do Sul - Unijuí, Ijuí/RS, Brasil robson.borges@unijui.edu.br https://orcid.org/0000-0001-7325-6910 


\title{
The change in the understanding of a trainee in Physical Education about the meaning of the curricular component at school: an autoetnography
}

\begin{abstract}
This research aimed to identify which factors induced a conceptual change of a graduating in Physical Education, in relation to the understanding of the meaning of this curricular component at school. Through self-ethnography, for 11 months the author analyzed the work done in academic tasks, the notes in notebooks of subjects taken, the interventions made as fieldwork and the questionnaires answered by his students. The results indicate that it was not a single event that led to a change in understanding, but several factors. The main one was the discussion, in a curricular component, about the students' right to learn. To a lesser extent, the interventions in fieldwork carried out by virtue of academic disciplines, the verification of the students' interest in experiencing teaching themes different from those they were used to and the testing of knowledge studied at the university with their own children, had an influence on the change conceptual.
\end{abstract}

KEYWORDS: School physical education; Traditional practices; Change of conception; Innovative practices; Autoethnography

\section{El cambio en la comprensión de un becario de Educación Física sobre el significado del componente curricular en la escuela: una autoetnografía}

\section{RESUMEN}

Esta investigación tuvo como objetivo identificar qué factores indujeron un cambio conceptual de un becario en Educación Física, en relación con la comprensión del significado de este componente curricular en la escuela. A través de la autoetnografía, durante 11 meses el autor analizó el trabajo realizado en las tareas académicas, los apuntes en cuadernos de materias cursadas, las intervenciones realizadas como trabajo de campo y los cuestionarios respondidos por sus alumnos. Los resultados indican que no fue un solo evento el que provocó un cambio en la comprensión, sino varios factores. El principal fue la discusión, en un componente curricular, sobre el derecho de los estudiantes a aprender. En menor medida, las intervenciones en el trabajo de campo realizadas en virtud de disciplinas académicas, la constatación del interés de los estudiantes por experimentar temas de enseñanza diferentes a los que estaban acostumbrados y la prueba de conocimientos estudiados en la universidad con sus propios hijos, habían una influencia en el cambio conceptual.

PALABRAS-CLAVE: Educación física escolar; Prácticas tradicionales; Cambio de concepción; Prácticas innovadoras; Autoetnografía 


\section{INTRODUÇÃO}

Ao final da segunda década do século 21 é possível apontar que a Educação Física escolar tem avançado em qualidade, mesmo que lentamente, quando o critério considerado para avaliação é o desenvolvimento de aulas de acordo com documentos legais da educação brasileira, como os Parâmetros Curriculares Nacionais e a Base Nacional Comum Curricular. O termo "lentamente" parece ser pertinente à medida que as aulas dessa disciplina, em sua maioria, ainda não se pautam pela tematização da diversidade das práticas corporais, bem como pela centralidade que deveria ganhar a aprendizagem dos conhecimentos específicos segundo previsto nos documentos mencionados (BRASIL, 1998; BRASIL, 2017). As atuações docentes identificadas como práticas tradicionais - nas quais são ensinados apenas alguns esportes com centralidade na execução de movimento - e os casos de abandono docente - nos quais os professores não empreendem esforços visando o aprendizado dos alunos sobre saberes específicos da Educação Física -, constituem-se como hegemônicos (BAGNARA; FENSTERSEIFER, 2016; VARGAS; MORISSO; GONZÁLEZ, 2017). Assim, o processo de "[...] romper com a lógica que sustentou o trabalho docente em Educação Física por quase um século" (GONZÁLEZ; FRAGA, 2012, p. 42), tem sido um processo lento e difícil.

Neste cenário, muitos acadêmicos ao começarem o curso de formação inicial em Licenciatura em Educação Física desconhecem a especificidade dessa área nas escolas, relacionada à tematização da cultura corporal de movimento. Boa parte dos estudantes acredita que as experiências que tiveram nas aulas dessa disciplina, enquanto alunos da Educação Básica, correspondem ao modo adequado de atuação profisssional.

Exatamente essa condição foi o caso do autor principal deste estudo ${ }^{1}$. Ao ingressar no Ensino Superior em Educação Física teve, assim como seus colegas, contato com diferentes práticas corporais. Essa situação foi um "choque", pois começou a perceber que seu entendimento inicial sobre a condição de "ser professor de Educação Física" estava distante do que apontam os marcos legais supracitados.

A perspectiva de uma Educação Física no viés das práticas inovadoras - que buscam ensinar os alunos a pluralidade de temas da cultura corporal de movimento e os respectivos

\footnotetext{
${ }^{1}$ Visando que os leitores entendam melhor o contexto de vida do autor, enquanto personagem deste enredo, mencionam-se os seguintes elementos individuais: acadêmico de Educação Física em uma universidade comunitária, casado, pai de dois filhos, trabalhando em diferentes funções (auxiliar de pedreiro, residente no Programa Residência Pedagógica, professor e coordenador de esportes - ao longo dos cinco anos como acadêmico, para prover renda familiar e estudar no Ensino Superior) e fazendo deslocamentos diários de $80 \mathrm{~km}$ entre a cidade em que residia e a universidade.
} 
conhecimentos vinculados (BRACHT, 2011; GONZÁLEZ, 2016; MALDONADO et al., 2018) - foi fazendo sentido com os anos de estudos na graduação, de modo que o professor em formação foi construindo uma noção de especificidade para esse componente curricular, a qual não fazia parte de suas concepções pré-universitárias, passando a compreender a disciplina de outra maneira. Dito de outro modo, passou a fazer sentido para o autor o entendimento de Betti (2013, p. 64) que defende a Educação Física na escola como:

[...] uma disciplina que tem por finalidade propiciar aos alunos a apropriação crítica da cultura corporal de movimento, visando a formar o cidadão que possa usufruir, compartilhar, produzir, reproduzir e transformar as formas culturais do exercício da motricidade humana: jogo, esporte, ginásticas e práticas de aptidão física, dança e atividades rítmicas/expressivas, lutas/artes marciais e práticas corporais alternativas.

Essa mudança de concepção sobre o sentido da Educação Física escolar foi extremamente significativa para ele, a tal ponto que atualmente o autor atua na função de professor dessa disciplina numa escola de uma cidade do interior do Rio Grande do Sul, desenvolvendo práticas inovadoras. De algum modo, o autor passou a defender que frente à variedade de temas a serem abordados na Educação Física - tais como: esportes, ginásticas, lutas, jogos motores, práticas expressivas, práticas corporais de aventura, atividades aquáticas, práticas corporais e sociedade e práticas corporais e saúde (RIO GRANDE DO SUL, 2009) -, não se pode considerar adequado que os alunos passem a vida escolar nessa disciplina tendo contato apenas com alguns esportes. Para atender ao direito de aprendizagem dos alunos, a Educação Física precisa oportunizar o contato com inúmeras possibilidades de movimento e práticas corporais diversas, para além daquelas que os alunos possuem em seu ambiente social - com a família, na igreja, entre outros - bem como os diferentes conhecimentos atreladas a essas manifestações. Assim, os discentes poderão construir novas referências sobre o seu corpo e formas de interagir com o meio no qual vivem (GONZÁLEZ; FENSTERSEIFER, 2009).

Sabendo que mudar a forma de compreender a Educação Física escolar e passar a atuar sob premissas inovadoras não é um acontecimento que se gera de forma espontânea em virtude da relação complexa entre aspectos micro (a cultura escolar) e macrossociais (a cultura mais geral) que demandam a necessidade de os docentes e os acadêmicos abandonarem as convicções prévias que, de certa forma, estão "enraizadas" - parece pertinente investigar o processo de transformação subjacente a essa mudança. Por isso, esta pesquisa tem como objetivo identificar quais fatores induziram uma mudança conceitual em 
relação à compreensão do sentido da Educação Física enquanto componente curricular na escola.

\section{PROCEDIMENTOS METODOLÓGICOS}

Este estudo se pauta numa abordagem qualitativa, caracterizando-se como uma autoetnografia implementada como forma de análise pessoal. A escolha por esse tipo de pesquisa se justifica por possibilitar uma "autoanálise" em busca de compreender a mudança conceitual pela qual o autor passou, em relação ao sentido da Educação Física na escola, comparando sua compreensão antes de iniciar a formação inicial e o entendimento atual, na condição de formando no referido curso.

As pesquisas qualitativas em Educação Física relacionadas à autoetnografia no Brasil são recentes. Este tipo de investigação quando centrada no trabalho dos professores de Educação Física, geralmente, busca informações de experiências dos docentes. Portanto, tem um caráter interpretativo no qual se procura uma compreensão da cultura a partir de um contexto particular investigado. Em outras palavras, a autoetnografia tem sido usada para conseguir ilustrar as experiências culturais, com o intuito de uma abordagem autocrítica para produção de novos conhecimentos (ROCHA; ARAÚJO; BOSSLE, 2018).

Considerando a relevância de destacar que somente a observação não possibilitaria uma interpretação em profundidade das experiências e envolvimento com um determinado contexto, Bossle et al. (2009) fizeram o uso de diferentes técnicas de levantamento de informações, o que permite uma descrição mais densa das vivências, sentimentos e aprendizagens do autoetnógrafo. Assim, observações, registros em diário de campo, diálogos informais e gravados são importantes porque permitem aproximar dados a partir de diferentes técnicas. Logo, são bastante utilizados nesse tipo de estudo uma vez que possibilitam aos pesquisadores descrever suas próprias vivências com a utilização dessas técnicas e passar para o leitor um determinado sentimento em relação aos procedimentos (BOSSLE et al., 2009).

O processo autoetnográfico tem como objetivo muito mais do que apresentar uma prática, procura entender o universo cultural particular do pesquisador. Isso pode, muitas vezes, levar o investigador a identificar e construir novos significados vinculados a diferentes perspectivas de uma prática específica. Nesse caso, é possível observar a prática "de dentro", através do protagonismo de quem pesquisa, por meio da análise da vivência que vem de um longo período e se pretende investigar. Dessa forma, o pesquisador estará em contato direto 
com um modo de agir particular, podendo gerar, a partir disso, novas significações (GOELLNER et al., 2010).

Para Kock, Godoi e Lenzi (2012), a autoetnografia corresponde a uma etnografia que aprofunda a pesquisa na consciência do indivíduo, relacionando-o com o meio no qual está inserido através da experiência pessoal. Logo, a escrita de uma autoetnografia procura narrar a história de uma vida na qual narrador e personagem se fundem numa mesma pessoa. Trata-se de um instrumento investigativo que traz o pesquisador como objeto ou sujeito de investigação.

Rocha, Araújo e Bossle (2018) afirmam que a autoetnografia é um desenho metodológico pouco utilizado na produção de conhecimento científico. Contudo, embora ainda incipiente, esse tipo de pesquisa tem ganhado espaço, sendo percebido como uma possibilidade de contribuir na melhor formação dos profissionais da educação. Nessa linha, Miranda e Bortoleto (2018) defendem que o "gesto autoetnográfico" oportuniza ao próprio pesquisador ser o objeto de pesquisa de forma objetiva.

Tendo em vista o uso recente da autoetnografia na Educação Física, Goellner et al. (2010) manifestam que muitos autores não conseguem alcançar o objetivo e se limitam a descrições superficiais. Com isso, as escritas que deveriam ser densas ficam abaixo do necessário, subscrevendo somente o observado. Por isso, a autoetnografia, diferente de outras técnicas de pesquisa, exige uma atenção especial. Enquanto alguns métodos se vinculam a linguagens técnicas, no momento de cruzar dados, comparar discursos, confrontar falas de diferentes sujeitos, a autoetnografia vai além, estruturando a vida social, em que todo valor, emoção ou atitude está escrita (GOELLNER et al., 2010).

Nessa linha de cuidados ao realizar a autoetnografia, Lopes (2012) adverte que um autoetnógrafo não deve se desinteressar ou subjugar o rigor científico, justificando no despojamento da escrita deslizes metodológicos. Nessa linha, Kock, Godoi e Lenzi (2012) destacam que na autoetnografia o pesquisador corre o risco constante da incapacidade de separação entre esferas, uma vez que estuda também a sua própria aprendizagem, em um contexto no qual está imerso, não somente para fins de pesquisa. Trate-se de narrar e questionar a própria dinâmica organizacional como professor. Afinal, o viver, o narrar e a compreensão estão presentes no processo autoetnográfico simultaneamente (KOCK; GODOI; LENZI, 2012).

Desse modo, aprender com a experiência, não só por meio da participação, mas da auto-observação dos acontecimentos vividos, é uma característica da autoetnografia. A 
recorrência a outras técnicas, além daquelas biográficas, é fundamental para a construção teórica ao final do estudo (KOCK; GODOI; LENZI, 2012).

Com o intuito de aprimorar os estudos relacionados à Educação Física, Goellner et al. (2010) destacam que os temas esportes e lazer estão ganhando espaço nas pesquisas autoetnográficas. Este movimento se entrelaça com a possibilidade de compreender o processo de reprodução cultural, levando o pesquisador a descobrir como se constroem e se desenvolvem as práticas da cultura corporal do movimento, que por estarem fortemente inseridas no cotidiano das pessoas, por vezes são confundidas como parte "natural" da vida. A partir desse pressuposto, a Educação Física se volta aos estudos etnográficos sobre as atividades diárias que se vinculam à área. Nessa linha, Goellner et al. (2010) mencionam que os autoetnógrafos creditam seus estudos à investigação e à análise de documentos, questionários, fotografias, mapeamentos, etc. Esse modelo se relaciona ao método artesanal de ciência, no qual cada investigador utiliza os modos que considera necessário para o levantamento de dados, articulando diferentes formas para identificá-las, um trabalho semelhante a um quebra-cabeça.

Assim, para elucidar como pesquisas de tom autoetnográfico têm sido desenvolvidas na área da Educação Física, na sequência constam alguns estudos que se valeram de tal abordagem. Num deles, Bossle et al. (2009) utilizaram a abordagem autoetnográfica ao estudarem uma escola de Porto Alegre/RS, justificando que a questão do trabalho coletivo na instituição, além de polêmica, permeia o discurso e o desejo dos gestores e do professorado, revelando-se de difícil visualização no cotidiano do trabalho pedagógico. A experiência autoetnográfica mostrou que a convivência, os sentimentos e o aprendizado durante uma autoetnografia proporcionou uma autorreflexão. Segundo os autores, a autoetnografia pode se constituir em um importante instrumento metodológico e de formação à medida que promove uma série de autorreflexões sobre a prática pedagógica, pela qual é possível reconhecer os sentimentos do próprio pesquisador, uma vez que ele é o sujeito da sua pesquisa, podendo compreender melhor suas práticas educativas.

Em outro estudo, Vitti (2011) descreve em uma autoetnografia a forma com que os saberes docentes influenciaram sua trajetória acadêmica. Segundo a autora, os sentimentos de desânimo estavam sempre presentes, pois na escola onde se encontrava, os professores se percebiam desacreditados e em situação de abandono docente. Nesse contexto, Vitti (2011, p. 33) destaca que "[...] refletir sobre a própria formação estando ainda em formação me dá a sensação de estar mais preparada para lidar com a realidade". 
O trabalho autoetnográfico de Lopes (2012), por sua vez, teve como objetivo compreender quais são os desafios pertinentes à docência em Educação Física na zona rural, a partir da reflexão do seu percurso formativo e do processo de construção do Projeto Político Pedagógico de escolas do campo. Neste contexto, a Educação Física pode compreender esta cultura corporal local como uma forma de integrar os interesses dos alunos e do Projeto Político Pedagógico.

\section{ANÁliSE E DISCUSSÃo dOS FATORES QUE INDUZIRAM A MUDANÇA CONCEITUAL}

Ao tentar identificar quais fatores induziram a mudança na compreensão sobre o sentido da Educação Física na escola, o autor realizou uma análise de sua trajetória como estudante universitário. Especificamente, de agosto de 2018 a junho de 2019, dedicou-se a buscar e analisar materiais que fizeram parte de seu percurso acadêmico. Na perspectiva da autoetnografia, considerou os seguintes materiais para apreciação: a) as anotações em seus cadernos utilizados em componentes curriculares cursados durante a formação inicial; b) os trabalhos realizados em disciplinas acadêmicas; c) as intervenções efetuadas como trabalho de campo $^{2}$; d) questionários respondidos por seus alunos.

No processo de análise desses materiais as ações foram pontuais. Primeiramente, o autor realizou a leitura de todas as anotações feitas nos cadernos de todas as disciplinas durante o curso de Educação Física. Quando encontrava algo que considerava ter relação com o objetivo desta pesquisa, destacava com uma caneta marca-texto. Posteriormente, efetuou ação semelhante em todos os trabalhos produzidos para atender as demandas dos componentes curriculares. Após, o autor centrou atenção nas intervenções realizadas em função dos afazeres de campo, efetuando uma busca em arquivos fotográficos e vídeos de trabalhos realizados.

Nesse processo, a análise dos documentos permitiu chegar aos seguintes fatores que induziram sua mudança de compreensão: 1) a discussão, em um componente curricular, sobre o direito de aprendizagem dos alunos; 2) as intervenções nos trabalhos de campo, realizadas em função de componentes curriculares; 3) a constatação do interesse dos alunos da escola,

\footnotetext{
2 As intervenções efetuadas como trabalho de campo se referem a todos os investimentos nos quais o autor interviu pedagogicamente com turmas de alunos em contexto real nas escolas, tanto por demandas de componentes curriculares, quanto de quatro estágios curriculares obrigatórios.
} 
ao experimentarem temas de ensino distintos dos que estavam acostumados; 4) a testagem de saberes estudados na universidade com os próprios filhos do autor.

Ao analisar o primeiro fator, é possível apontar que a discussão sobre o direito de aprendizagem dos alunos realizada num componente curricular foi o principal aspecto que induziu a mudança conceitual do autor. Participar das reflexões sobre essa temática o marcou fortemente, pois percebeu que a ideia de direito dos discentes remete ao dever do professor. Pontualmente, encontrou nas anotações no caderno de uma das disciplinas do primeiro semestre uma fala de um docente sobre isso: "Vocês têm que pensar que não estão prestando um favor e levar em conta que os alunos têm o direito de aprender e o professor tem o dever de ensinar!". Essa fala deixou-o intrigado, afinal nunca havia pensado sobre isso.

Ao refletir sobre essa temática, inevitavelmente, suas reflexões se voltaram para as aulas de Educação Física que teve com três professores em uma escola pública estadual, pois percebeu que seu direito de aprendizado sobre os diversos temas relacionados à cultura corporal de movimento não foi garantido. Sem intenção de julgar os professores, supõe-se que eles não se comprometeram com a efetivação de tal direito por falta de conhecimento. Como Borges (2019, p. 179) defende: “[...] o despreparo dos professores quanto ao conhecimento sobre conteúdos pertinentes à EF escolar minimiza a possibilidade de trabalhar com a pluralidade de temas da cultura corporal de movimento. Com isso, o direito de aprendizagem dos alunos se reduz".

Neste contexto, durante as primeiras aulas do componente curricular "Estrutura dos Esportes I" ${ }^{\prime 3} \mathrm{o}$ autor passou a compreender que a ideia de direito de aprendizagem dos alunos era uma questão central na Educação Física escolar. A partir disso, começou a analisar se estava preparando-se adequadamente para se tornar um professor que conseguiria garantir esse direito aos alunos. Essa reflexão o acompanhou durante toda a formação inicial.

Ainda nesse componente curricular, tomou contato com diversos conteúdos e possibilidades de estudo que a Educação Física oferece, especialmente em relação aos esportes. A partir disso, durante as aulas na universidade, começou a notar que aquilo que acreditava ser "adequado" em relação ao ensino da Educação Física antes de iniciar o Ensino Superior, estava cada vez mais distante. Então percebeu que "ser professor de Educação Física" ia muito além do seu entendimento antes do curso e seria necessário estudar bastante. Desse modo, sua convicção sobre o direito dos alunos a aprender, inclusive, serviu para enfrentar, por meio de diálogos, a resistência de seus alunos a realizarem as atividades

\footnotetext{
${ }^{3}$ Componente curricular do primeiro semestre do curso de Educação Física da Unijuí - Projeto Pedagógico de Curso versão 2015.
} 
propostas nas aulas de Educação Física em suas primeiras intervenções. Lembra-se que nestes casos utilizava uma frase dita por um docente em sua formação inicial: "Vocês não têm a opção de não fazer, de não praticar, a não ser por um problema de saúde. Certos conhecimentos na Educação Física precisam da experimentação corporal”. Com isso, deixava claro para os alunos parte dos direitos e deveres durante as aulas. Tal compreensão permitia defender que se os alunos têm o direito de aprender e o professor o dever de ensinar, em contrapartida, o docente tem o direito de cobrar e os discentes o dever de colaborar, como em qualquer outro componente curricular na escola.

Esse entendimento sobre o destaque na reflexão acerca do direito dos alunos em aprender, é similar ao encontrado por Borges (2019). Em recente pesquisa, o referido autor identificou que o principal fator - apontado por professores participantes de uma formação continuada de longa duração - que proporcionou uma mudança na forma de compreender a Educação Física escolar, foi o estudo sobre o direito dos alunos em aprender a pluralidade de temas vinculados à cultura corporal de movimento como finalidade dessa disciplina na escola. Esse aspecto merece atenção, pois, como Behrens (2007) defende, o envolvimento e o compromisso com as aprendizagens do aluno podem ser fundamentais para o sucesso da formação de professores.

Em relação ao segundo fator, o autor deste estudo considera que a realização dos trabalhos de campo, por ocasião de componentes curriculares de seu curso, foi o segundo elemento que possibilitou a mudança de compreensão sobre o sentido da Educação Física. Por meio das intervenções ele percebeu a relevância de trabalhar com práticas inovadoras e conteúdos diversificados.

As atividades realizadas em escolas permitiram perceber a viabilidade de desenvolvimento do que estava sendo estudado em sua formação inicial. Assim, ao longo dos anos na universidade realizou a "testagem", com diferentes turmas de alunos, do planejamento e da implantação de vários temas curriculares. Diante disso, como exemplo, na sequência constam algumas imagens de aulas realizadas.

Quadro 1 - Exemplos de "testagem" de saberes nas escolas, em função dos trabalhos de campo 


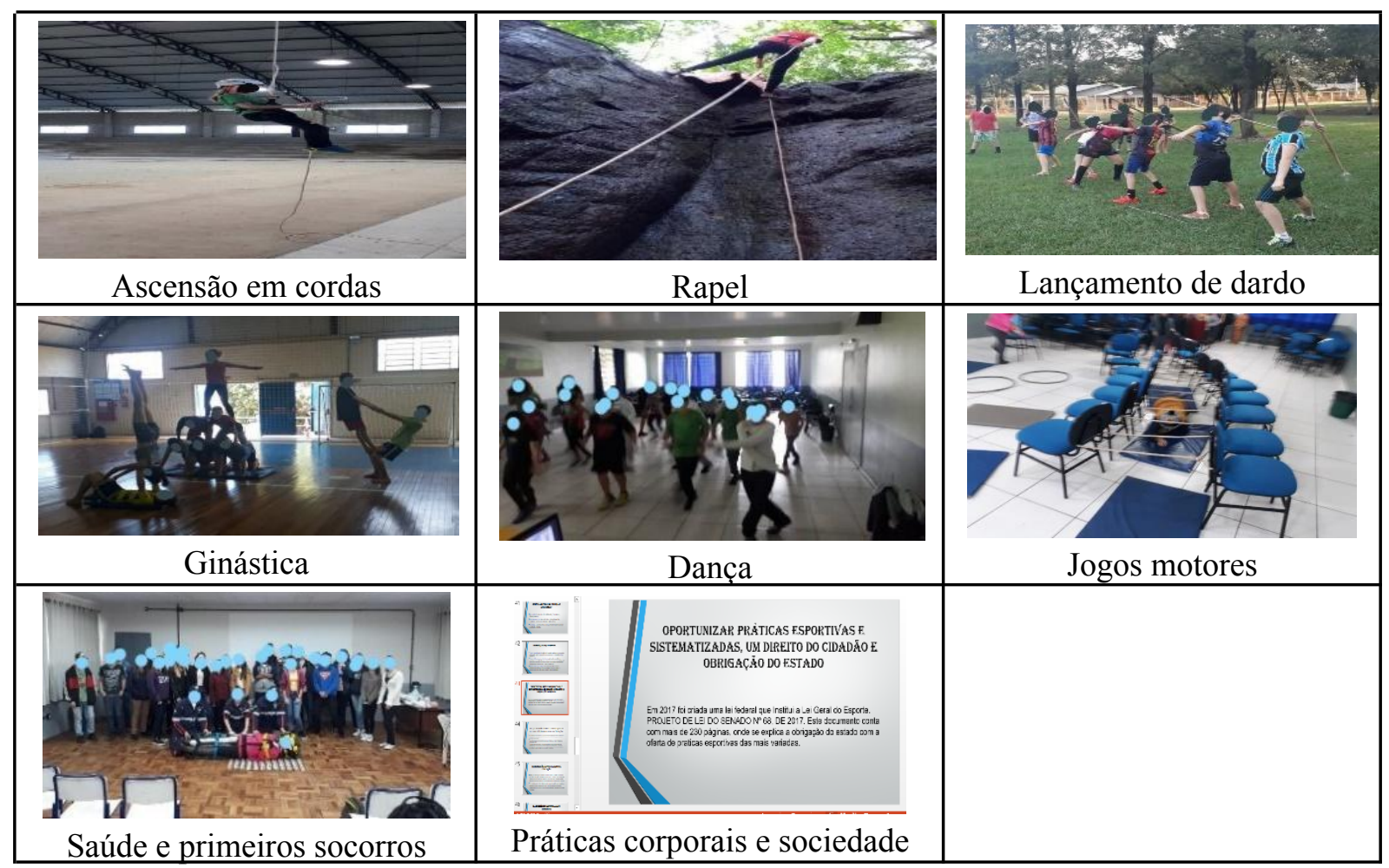

Fonte: Acervo pessoal do autor

Para o autor, os trabalhos de campo solicitados nas diferentes disciplinas permitiram testar e evidenciar ser possível ministrar aulas de Educação Física sobre diferentes manifestações da cultura corporal de movimento e de modo inovador. Como explica Rezer (2007), acerca da realização de trabalhos de campo, é preciso de forma concreta realizar e proporcionar aos acadêmicos a produção de intervenções dentro das escolas, sendo que essas ações devem ser mais divulgadas e expandidas, com a intenção de não serem reconhecidas somente por pequenos grupos. Através disso, Rezer (2007) entende que se pode favorecer "rupturas" em concepções tradicionais, visando mudanças na Educação Física que configurem destaque às práticas pedagógicas na escola.

Em síntese, as intervenções por ocasião dos vários trabalhos de campo permitiram ao autor perceber a Educação Física de outra forma, quando comparada ao que vivenciou como aluno na Educação Básica. Inclusive, as aulas ministradas durante as intervenções de campo reconhecidas como "diferentes" e elogiadas pela comunidade escolar (professores, pais e alunos) - lhe possibilitaram continuar na escola como professor com vínculo empregatício no 
Município $^{4}$. Com isso, pôde seguir experimentando/testando tudo o aprendido durante as aulas na universidade.

$\mathrm{Na}$ condição de docente na escola percebeu uma semelhança nas ações que desenvolvia nessa função, com os resultados encontrados por González e Borges (2015). Ao tentarem identificar nos saberes mobilizados por uma professora de Educação Física em sua atuação docente, elementos de sua formação inicial, os autores concluíram que

[...] grande parte dos saberes docentes manifestados pela docente, em sua atuação profissional, podem ser apontados como oriundos da formação inicial. Evidências disso podem ser constatadas observando a 'pluralidade' das práticas corporais desenvolvidas e na forma de ensino dos esportes, pautada na tomada de decisão nos jogos de invasão, o que coincide com os princípios defendidos pelo curso de formação inicial que a docente frequentou (GONZÁLEZ; BORGES, 2015, p. 36).

$\mathrm{Na}$ análise do terceiro fator, o autor identificou que o interesse dos alunos ao experimentarem temas de ensino distintos dos que estavam acostumados foi uma espécie de constatação da viabilidade do trabalho na perspectiva das práticas inovadoras. A "resistência" dos alunos em não querer participar das tarefas diferentes de "jogar bola", durou pouco tempo. Após três semanas do início do desenvolvimento da primeira unidade didática, eles manifestaram satisfação com aulas distintas do que estavam acostumados, como se percebe nos seguintes depoimentos de discentes sobre as possibilidades de novas práticas: "Foi uma experiência muito positiva, trouxe ideias novas para a Educação Física que é a mesma coisa sempre, realizando atividades que nunca haviam sido feitas na escola" (Aluno Sandro5); "Todos esses anos a Educação Física foi muito monótona" (Aluna Maria); "Foram experiências bem diferentes daquilo que já tínhamos praticado antes, muito interessante e irei levar isso comigo. Foi único" (Aluno Pedro); "Positivo é ter a oportunidade de praticar algo novo e se desafiar, sendo que não precisa pagar. Destaco como negativo, ver que muitos não têm essa experiência gratuitamente" (Aluno Carlos); "As aulas foram muito importantes para conhecer novas práticas e ter aprendizados que não eram conhecidos por muitos. Para descobrir novos gostos" (Aluno Cristian); "Seria muito importante ter esse tipo de prática diferenciada nas aulas de Educação Física, pois também são necessárias” (Aluna Mainara); “Até agora muitas pessoas olham a Educação Física como futebol e vôlei, mas ela é muito

\footnotetext{
${ }^{4}$ Mediante a atuação docente do autor em uma escola pública municipal, considerada "diferente" positivamente em relação ao que era desenvolvido anteriormente nas aulas de Educação Física, a gestão municipal local ofereceu um vínculo empregatício por meio de um cargo de confiança, para que o autor continuasse seu trabalho na escola de forma remunerada e atuasse como coordenador de esportes no município. Assim, é possível afirmar que a dimensão do reconhecimento do trabalho pela comunidade escolar, proporcionou e se materializou na possiblidade do vínculo empregatício.

${ }^{5}$ Os nomes dos alunos são fictícios.
} 
mais que isso, e falando mais uma vez... Eu amei a prática do rapel e só a Educação Física pode me proporcionar isso" (Aluno Rafael); “A Educação Física nunca me pareceu tão ampla, não sabia da metade das coisas que estavam nela" (Aluno Manoel); "Saímos da nossa zona de conforto que era futebol e vôlei. Essas novas práticas apresentadas despertaram um novo interesse" (Aluna Rafaela).

Quadro 2 - Imagens de respostas de alunos a um questionário ao final de um ano letivo

\begin{tabular}{|c|}
\hline 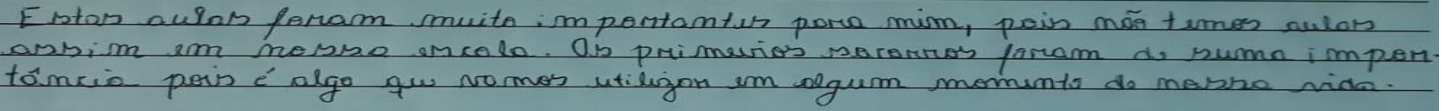 \\
\hline 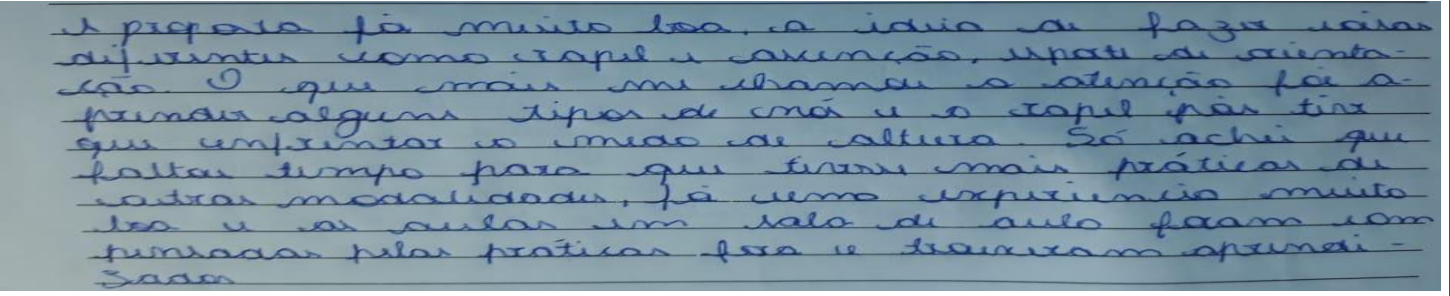 \\
\hline
\end{tabular}

Fonte: acervo pessoal do autor

Ter tido a oportunidade de realizar diversos trabalhos no campo profissional, tematizando diferentes manifestações da cultura corporal de movimento, permitiu ao autor, via o reconhecimento dos alunos, perceber a importância de o professor de Educação Física propiciar práticas inovadoras, indo bem além do que ele imaginava como suficiente antes de ingressar a universidade. Neste sentido, receber ao final de cada unidade didática, feedback positivos do alunado sobre a experiência, reforçou sua conviç̧ão sobre o valor de garantir o acesso a outras práticas corporais além dos esportes.

Essa constatação da satisfação dos alunos com práticas diferentes do que estavam acostumados surpreendeu o autor, uma vez que esperava uma forte resistência. Resultado similar foi apresentado por Tamiozzo (2018) quando identificou que o docente de Educação Física participante de sua pesquisa, surpreendeu-se com a aceitação/participação dos discentes em aulas de ginástica, pois ele acreditava que os alunos não iriam gostar/participar de um conteúdo diferente dos jogos esportivos. Esse achado, ratifica a apuração de González (2006, p. 101): "a resistência dos alunos a uma nova forma de trabalho, em geral, é sempre inferior ao que se imagina antes de propô-la e inversamente proporcional à convicção do professor sobre a pertinência da mesma".

Desta forma, a realização de novas práticas tende a tornar os discentes mais críticos em relação aos conhecimentos que a Educação Física escolar pode proporcionar. De alguma 
maneira, quando o autor deste estudo percebeu, estava desenvolvendo com alunos algo que sequer sabia que existia quando era aluno na Educação Básica.

Finalmente, ao analisar o último fator, o autor entende que a testagem de conhecimentos - estudados na universidade - com seus próprios filhos fortaleceu sua compreensão sobre a pertinência do desenvolvimento de conteúdos da Educação Física. Especificamente, em função da demanda do componente curricular "Bases da Motricidade Humana" , realizou um trabalho sobre desenvolvimento motor com meus filhos (um menino e uma menina, atualmente com sete e 11 anos de idade, respectivamente). Nessa oportunidade, percebeu a influência dos estímulos que um profissional da Educação Física pode proporcionar para uma criança e o quanto um trabalho adequado possibilita o desenvolvimento motor e cognitivo.

Esse trabalho possibilitou ao autor notar uma diferença considerável no domínio das habilidades básicas de seus dois filhos. O menino, com de três anos de idade na época em que o trabalho da disciplina foi realizado, estava na fase motora fundamental em estágio maduro passando para o estágio transitório da próxima fase, a motora especializada (GALLAHUE; OZMUN, 2001), o que seria esperado para uma criança de seis a sete anos. Já filha de sete anos de idade, encontrava-se no estágio elementar da fase motora fundamental (GALLAHUE; OZMUN, 2001), o que é comum para crianças com idade entre quatro e cinco anos. $\mathrm{Na}$ sequência constam imagens desse trabalho (Figura 3).

Figura 3 - Imagens do trabalho sobre desenvolvimento motor

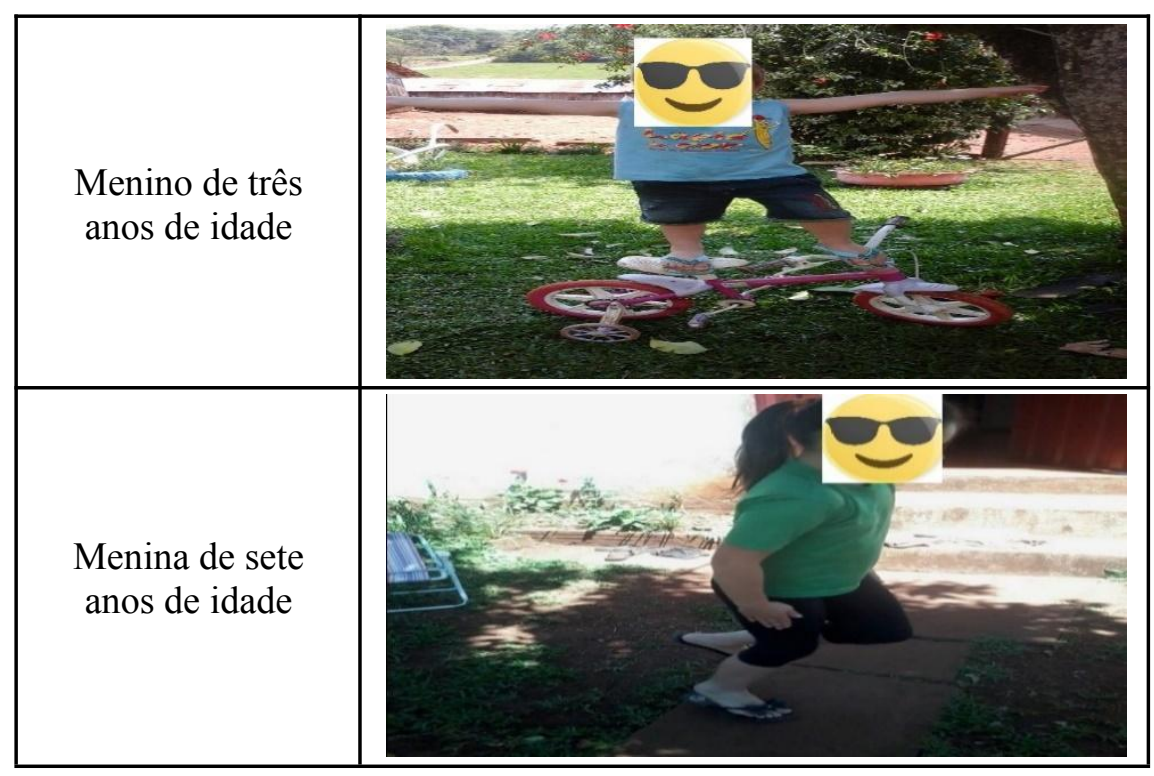

Fonte: Acervo pessoal do autor

\footnotetext{
${ }^{6}$ Componente curricular do quarto semestre do curso de Educação Física da UNIJUí - Projeto Pedagógico de Curso versão 2015.
} 
O autor, a partir dessa experiência, reafirmou sua convicção de quanto é importante o trabalho do professor, bem como o compromisso dele com a aprendizagem de seus alunos. Afinal, ao dimensionar a contribuição que ele poderia ter no desenvolvimento de seus filhos, também conseguiu perceber que, enquanto docente, seu trabalho poderia fazer muita diferença no desenvolvimento de outras crianças. Na sequência, como exemplo, consta uma imagem de um dos trabalhos realizados pelo autor visando o desenvolvimento motor de escolares (Figura 4).

Figura 4 - Circuito motor com as turmas da Educação Infantil: Pré-Escolar 1 e 2

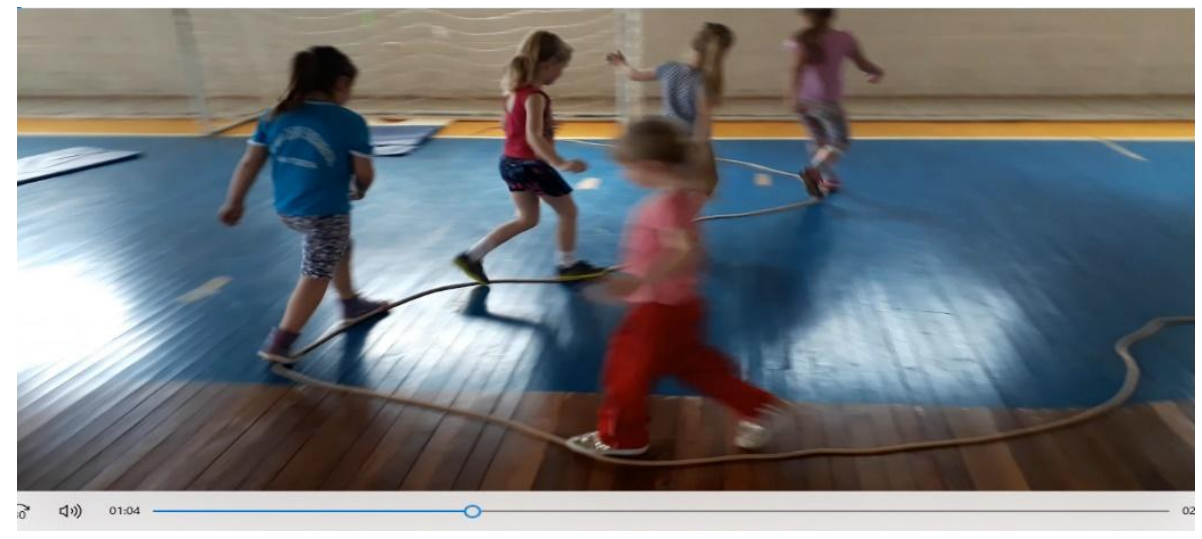

Fonte: Acervo pessoal do autor

Assim, o fato de utilizar seus filhos como "cobaias" permitiu verificar a importância da aquisição de conhecimentos estudados na universidade para garantir a aprendizagem das crianças. Os resultados obtidos nos trabalhos reforçaram o entendimento que deveria se dedicar - dentro de seus limites - fortemente aos estudos de todas as disciplinas. Afinal, como aponta Rezer (2007, p. 54), “[...] dominar conceitos, metodologias e procedimentos didático-pedagógicos, e não somente exemplos de jogos, por exemplo, permite construir uma infinidade de situações de aula, com maior autonomia pedagógica, em qualquer contexto".

O trabalho em questão, lhe permitiu vivenciar, na condição de pai, o desejo de reivindicar que seus filhos tenham a oportunidade de aprender tudo o que a Educação Física pode oferecer, bem como projetar o quanto seria pernicioso para eles que essa chance fosse negada por falta de preparação ou desídia dos docentes. Por analogia, percebeu que para garantir o direito de aprendizagem de seus alunos ele precisava estudar muito e assim se constituir num professor capaz de trabalhar com práticas inovadoras na Educação Física escolar. Assim, tal como identificado por Vitti (2011), o autor compreende que refletir sobre a 
própria formação - estando ainda em formação - gerou o sentimento de estar mais preparado para lidar com a realidade, o que confere crédito à utilização da autoetnografia.

Ao refletir sobre os fatores apresentados e pensando a partir de Tardif (2014), entende-se que os saberes disciplinares tiveram destaque no processo de mudança conceitual pelo qual o autor passou. O contato com conhecimentos que permeiam a Educação Física escolar durante sua formação, permitiu-lhe uma leitura mais ampla da área, possibilitando uma atuação docente pautada em práticas inovadoras, algo que para era desconhecido antes do seu ingresso no Ensino Superior.

\section{CONSIDERAÇÕES FINAIS}

A realização de um estudo autoetnográfico permitiu o autor analisar seu percurso como estudante e professor de Educação Física, na condição de pesquisador de suas próprias práticas. Por meio de uma autoetnografia, na qual o autor foi o próprio sujeito investigado, ocorreu uma reflexão crítica dos anos de investimento na formação profissional.

Como resposta para a questão geradora desta pesquisa, quatro fatores foram identificados destacadamente como propiciadores da mudança na compreensão do sentido da Educação Física escolar pelo autor. O principal deles foi a discussão, durante uma disciplina na graduação, sobre o direito de aprender dos alunos, uma vez que ficou "tocado" com a constatação de que o direito dos alunos nas aulas de Educação Física nem sempre é garantido. Aliado a isso, as vivências nos trabalhos de campo por ocasião de componentes curriculares, a constatação do interesse dos discentes ao experimentarem temas de ensino diferentes dos que estavam acostumados e a testagem de conhecimentos estudados na formação inicial com seus próprios filhos, foram fundamentais para sua "virada conceitual".

Essa constatação talvez seja um indicativo com destacável potencial na tentativa de superar lacunas na formação de professores em duas linhas. Na primeira, que as instituições formadoras de docentes para atuar na Educação Física escolar precisam dedicar atenção à reflexão dos acadêmicos acerca do sentido dessa disciplina na escola, proporcionando desde o começo de sua formação uma mudança nas "lentes" que eles utilizam, ou seja, oportunizar que os alunos reflitam sobre a especificidade da área de acordo com os marcos legais (BRASIL, 1998, 2017), tornando-se mais críticos para que possam atuar com práticas inovadoras e atender o direito de aprendizagem dos alunos. Algo no sentido de descontruir o imaginário sobre a Educação Física que boa parte dos alunos chega ao Ensino Superior. Além disso, as universidades poderiam aumentar as vivências profissionais na escola por meio de 
trabalhos de campo, acompanhados de uma leitura consistente dos impactos dos mesmos na vida dos alunos, para que os acadêmicos possam realizar uma conexão entre o que estudam e a realidade escolar.

$\mathrm{Na}$ segunda linha, os alunos de licenciatura em Educação Física poderiam "se envolver" mais efetivamente com os trabalhos de campo. Refere-se com isso, a um comprometimento para além de apenas obter notas para serem aprovados nas disciplinas, mas perceberem as intervenções na escola como uma condição imprescindível de preparação para atuação docente na perspectiva inovadora. Estar disposto à reflexão, tanto sobre a especificidade da Educação Física escolar quanto ao engajamento com os trabalhos de campo, pode fazer a diferença na constituição profissional, como foi o caso do autor.

Em um estudo futuro, pretende-se investigar casos opostos ao tratado nesta pesquisa. Especificamente, a ideia é pesquisar como acadêmicos de Educação Física que passaram por experiências semelhantes ao que o autor deste estudo passou, não são "tocados" pela ideia de especificidade dessa disciplina vinculada à tematização da pluralidade de práticas corporais como direito dos alunos, ao ponto de atuar numa perspectiva tradicional ou mesmo em situações de abandono docente na escola nos primeiros anos de atuação profissional.

\section{REFERÊNCIAS}

BAGNARA, Ivan C.; FENSTERSEIFER, Paulo E. Intervenção pedagógica em Educação Física: um recorte da escola pública. Motrivivência, v. 28, p. 316-330, 2016. Disponível em:

https://periodicos.ufsc.br/index.php/motrivivencia/article/view/2175-8042.2016v28n48p316. Acesso em: 08 jun. 2021.

BEHRENS, Marilda A. O paradigma da complexidade na formação e no desenvolvimento profissional de professores universitários. Educação. Porto Alegre/RS, ano XXX, n. 3 (63), p. 439-455, 2007.

Disponível em: https://core.ac.uk/download/pdf/25531643.pdf. Acesso em: 08 jun. 2021.

BETTI, Mauro. Educação física escolar: ensino e pesquisa-ação. Ijuí: Ed. Unijuí, 2013.

BORGES, Robson M. Estudar com professores: a formação continuada e o processo de mudança de concepção de ensino na Educação Física escolar. Curitiba: CRV, 2019.

BOSSLE, Fabiano et al. Autoetnografia: Possibilidades de Investigação e de Formação no Âmbito da Educação Física. In: BRASIL. Lei de Diretrizes e Bases da Educação Nacional. Lei n. 9.394/96.

Congresso Brasileiro de Ciências do Esporte e III Congresso Internacional de Ciências do Esporte,16., 2009, Salvador. Anais... Salvador, 2009. Disponível em:

http://cev.org.br/arquivo/biblioteca/4033547.pdf. Acesso em: 08 jun. 2021. 
BRACHT, Valter. Dilemas no cotidiano da Educação Física escolar: entre o desinvestimento e a inovação pedagógica. Salto para o Futuro. TV Escola. Ano XXI Boletim 12, Set. 2011. p. 14-20. Disponível em:

http://cev.org.br/arquivo/biblioteca/dilemas-cotidiano-educacao-fisica-escolar-entre-o-desinvestimento -e-inovacao-pedagogica.pdf. Acesso em: 08 jun. 2021.

BRASIL. República Federativa do. Parâmetros Curriculares Nacionais: educação física. Brasília: Secretaria de Educação Fundamental, 1998.

BRASIL. República Federativa do. Ministério da Educação. Base nacional comum curricular: educação é a base. Brasília: Ministério da Educação, 2017. Disponível em: http://basenacionalcomum.mec.gov.br/images/BNCC_20dez_site.pdf. Acesso em: 15 abr. 2019.

GALLAHUE, David L.; OZMUN, John C. Compreendendo o desenvolvimento motor: bebês, crianças, adolescentes e adultos. São Paulo: Phorte, 2001.

GOELLNER, Silvana V. et al. Pesquisa qualitativa na educação física brasileira: marco teórico e modos de usar. Rev. da Educação Física/UEM, Maringá, v. 21, n. 3, p. 381-410, 2010. Disponível em: https://periodicos.uem.br/ojs/index.php/RevEducFis/article/view/8682/5829. Acesso em: 08 jun. 2021.

GONZÁLEZ, Fernando J. Projeto curricular e educação física: o esporte como conteúdo escolar. In: REZER, Ricardo (org.). O fenômeno esportivo: ensaios crítico-reflexivos. Chapecó: Argos, 2006. p. 69-109.

GONZÁLEZ, Fernando J. Atuação dos professores na Educação Física escolar: entre o abandono do trabalho docente e a renovação pedagógica. In: SILVA, Paula C. C. et al. (Org.). Territorialidade e diversidade regional no Brasil e América Latina: suas conexões com a Educação Física e as Ciências do Esporte. v. 1. Florianópolis: Tribo da Ilha, 2016. p. 123-136.

GONZÁLEZ, Fernando J.; BORGES, Robson M.; Conhecimentos Acadêmicos, Saberes e Afazeres Pedagógicos do Professor de Educação Física: Mapeando Vínculos. Motrivivência, v. 27, n. 44, p. 36-48, maio, 2015. Disponível em:

https://periodicos.ufsc.br/index.php/motrivivencia/article/view/2175-8042.2015v27n44p36. Acesso em: 08 jun. 2021.

GONZÁLEZ, Fernando J.; FENSTERSEIFER, Paulo E. Entre o "não mais" e o "ainda não": pensando saídas do não-lugar da EF escolar I. Cadernos de Formação RBCE, p. 9-24, set. 2009. Disponível em: http://www.unesc.net/portal/resources/files/354/entre_o_nao_mais_e_o_ainda_nao.pdf. Acesso em: 08 jun. 2021.

KOCK, Klara F.; GODOI, Christiane K.; LENZI, Fernando C. Discussão e prática da autoetnografia: um estudo sobre aprendizagem organizacional em uma situação de catástrofe. Rev. Gestão Organizacional, vol. 5, n. 1, Blumenau, p. 93-109, 2012. Disponível em: https://bell.unochapeco.edu.br/revistas/index.php/rgo/article/view/1249. Acesso em: 08 jun. 2021.

LOPES, Rodrigo A. Semear-se (em) um campo de dilemas: uma autoetnografia de um professor de Educação Física principiante na zona rural de Ivoti/RS. 311 f. Dissertação de Mestrado pelo programa de Pós-Graduação em Educação da Universidade do Vale dos Sinos- UNISINOS, São Leopoldo, 2012.

MALDONADO, Daniel T. et al. Indícios de mudanças na prática pedagógica dos professores de Educação Física Escolar: análise dos estudos publicados em anais de eventos nacionais.

Corpoconsciência (São Paulo), v. 22, n. 1, p. 101-116, 2018. Disponível em: https://periodicoscientificos.ufmt.br/ojs/index.php/corpoconsciencia/article/view/6279. Acesso em: 08 jun. 2021. 
MIRANDA, Rita C. F.; BORTOLETO, Marco A. C. O Circo na Formação Inicial em Educação Física: um Relato Autoetnográfico. Rev. Bras. Ciênc. Esporte, São Paulo, v. 40, n. 1, p. 39-45, 2018.

Disponível em:

https://www.scielo.br/j/rbce/a/MRQ6kxTSRXZDZpdD4vKnmWD/?lang=pt\&format=pdf. Acesso em: 08 jun. 2021.

REZER, Ricardo. Relações entre conhecimento e prática pedagógica no campo da Educação Física: pontos de vista... Motrivivência, ano XIX, no 28, p. 38-62, 2007. Disponível em:

https://periodicos.ufsc.br/index.php/motrivivencia/article/view/9122/9550. Acesso em: 08 jun. 2021.

RIO GRANDE DO SUL. Referencial curricular de Educação Física. In: RIO GRANDE DO SUL. Secretaria de Estado da educação. Departamento Pedagógico. Referenciais Curriculares do Estado do Rio Grande do Sul: linguagens, códigos e suas tecnologias: arte e educação física. Porto Alegre: SE/DP, 2009. v. 2, p. 111-181.

ROCHA, Leandro O.; ARAÚJO, Samuel N.; BOSSLE, Fabiano. Autoetnografia, Ciências Sociais e Formação Crítica: Uma Revisão da Produção Científica da Educação Física. Rev. Int. de Form. de Professores (RIFP), v. 3, n. 4, p. 168-185, out./dez., 2018. Disponível em:

https://periodicoscientificos.itp.ifsp.edu.br/index.php/rifp/article/view/368/156. Acesso em: 08 jun. 2021.

TAMIOZZO, Fernando H. O estudo colaborativo como forma de reflexão na Educação Física escolar: um estudo de caso sobre o ensino da ginástica geral. 2016. 49 f. Trabalho de Conclusão de Curso (Graduação em Educação Física) - Universidade Regional do Noroeste do Estado do Rio Grande do Sul. Ijuí/RS, 2018.

TARDIF, Maurice. Saberes Docentes e Formação Profissional. Petrópolis: Vozes, 2014.

VITTI, Camila C. Refletindo sobre a própria prática: um estudo autoetnográfico sobre os saberes de uma professora em form(ação). $38 \mathrm{f}$. Trabalho de Conclusão de Curso apresentado ao curso de Pedagogia - licenciatura da Universidade Estadual Paulista, Instituto de Biociências de Rio Claro, 2011.

\section{NOTAS DE AUTOR}

AGRADECIMENTOS - Não se aplica.

CONTRIBUIÇÃO DE AUTORIA - Não se aplica.

FINANCIAMENTO - Não se aplica.

CONSENTIMENTO DE USO DE IMAGEM - Não se aplica.

APROVAÇÃO DE COMITÊ DE ÉTICA EM PESQUISA - Não se aplica.

CONFLITO DE INTERESSES - Não se aplica.

\section{LICENÇA DE USO}

Os autores cedem à Motrivivência - ISSN 2175-8042 os direitos exclusivos de primeira publicação, com o trabalho simultaneamente licenciado sob a Licença Creative Commons Attribution Non-Comercial ShareAlike (CC BY-NC SA) 4.0 International. Esta licença permite que terceiros remixem, adaptem e criem a partir do trabalho publicado, desde que para fins não comerciais, atribuindo o devido crédito de autoria e publicação inicial neste 
periódico desde que adotem a mesma licença, compartilhar igual. Os autores têm autorização para assumir contratos adicionais separadamente, para distribuição não exclusiva da versão do trabalho publicada neste periódico (ex.: publicar em repositório institucional, em site pessoal, publicar uma tradução, ou como capítulo de livro), com reconhecimento de autoria e publicação inicial neste periódico, desde que para fins não comerciais e compartilhar com a mesma licença.

\section{PUBLISHER}

Universidade Federal de Santa Catarina. Programa de Pós-Graduação em Educação Física. LaboMídia - Laboratório e Observatório da Mídia Esportiva. Publicado no Portal de Periódicos UFSC. As ideias expressadas neste artigo são de responsabilidade de seus autores, não representando, necessariamente, a opinião dos editores ou da universidade.

\section{EDITORES}

Mauricio Roberto da Silva, Giovani De Lorenzi Pires, Rogério Santos Pereira.

\section{EDITOR DE SEÇÃO}

Juliano Silveira.

\section{REVISÃO DO MANUSCRITO E METADADOS}

João Caetano Prates Rocha; Keli Barreto.

\section{HISTÓRICO}

Recebido em: 13 de abril de 2021.

Aprovado em: 01 de junho de 2021. 